\section{A LCOHOLIC PARAPLEGIA.}

\section{BY SAMUEL WILKS, M.D.} PHYSICIAN TO GUY'S HOSPITAI.

The above name is one $I$ have long used in reference to class of cases which are not at all uncommon, but have 3een hitherto left undescribed, in a manner worthy of S 3 im importance, in systematic works on medicine. In my probished lectures on Diseases of the Nervous System I Griefly referred to the affection as one requiring our earnest wognition, and gave some particulars of the cases which 7 had then seen. Since that time several others have come neder my notice, and during the last year no less than four nore. These facts had led me to commence a paper for the wanideration of one of the medical societies, when I met with an essay by Dr. Handfield Jones, contained in the Proctitioner of last month, on "Epilepsy and other Nervous neetions resulting from the excessive use of Alcohol." A perusal of this essay shows me that my object is now uninecessary, and that I need do little more than recommend its attentive perusal to the readers of THE LANCET, and say for my own part that I can endorse nearly all the statements therein contained. I have seen epilepsy and many other nervous diseases result from alcohol, although my attention has been more especially drawn to the spinal a ffection. In srder, however, to strencthen Dr. H. Jones's statements, I ¥ill quote from a lecture given by me in October, 1867, as 践 contains an epitome of what I had then observed :-

Drunlards' or Alcokolic Paraplegia.-I do not know that this is deserving of a distinct name from its possessing any \$athological peculiarities; but as arising in connexion with very well maxked exciting cause, it may deserve your expecial attention, and I refer to it the more especially bewasse I believe authors have generally overlooked it. I have Slready told you how long-continued habits of intemperance alcoholic drinks tend to the production of a fibrous or Inty degeneration of the various tissues of the body, and is ats as a consequence, the membranes of the brain and soinal cord become thickened, and the organs within wasted. This, of course, would give rise to what might be talled a general paralysis of body and mind. But besides fhese general results, we of ten meet with more direct effects son the spinal cord, and to these I particularly refer. I have 3ar seen so many persons, especially ladies, who have en Hiroly given themselves op to the pleasures of brandyarinking, and been rendered paraplegic, that I have become presty familiar with the symptoms. From what we hear of ow continental neighbours, it would seem that the diaBolical compound styled 'absinthe' is productive of exsaastion of nervous power in even a much more marked degree; it wonld appear that the volatile oils dissolved in the aleohol give additional force to its poisonous effects. Of aurse, drunkards of all descriptions suffer from nervous and muscular weakness; but, as $I$ before said, it is more apecially in the legs that the effect is most striking. A Dons of power is first observed, accompanied by pains in the 3imbs, which might indicate a chronic meningitis of the apinal cord, and in some cases there is anæsthesia. There at the same time, some amount of feebleness of other iparts of the body as well as the mind, and thus an approach so general paralysis is produced; but sometimes the symptoms are almost confined to the legs, and resemble in chasacter those of locomotor ataxy."

Since this was written I have seen several cases of a jimilar kind; and it is wortiny of remark that they occurred mostly in women. I would repeat that something more definite is intended by the term "alcoholic paralysis" than that general muscular and nervous debility which is as well known to the public as the profession; for no character is more easily recognised on the stage of the theatre than the victim of chronic drunkenness. That which I wish more particularly to draw attention to, is the case where alcohol is seen exerting its influence more directly on the spinal eord, making paralysis the leading symptom. Although there is a tendency to a particular form of degeneration in alcoholisin, it is not very evident why one person should be sifected in one way and another in another; or why one Jerson should have cirrhosis of the liver, another Bright's disease, and a third atrophic meningo-cerebro-myelitis. I use this term since the changes which the brain and spinal marrow undergo are probably identical with those which are found in the two other affections just mentioned. As regards the brain, the tissue degenerates and the mem branes become thickened, and thus the mental condition of the " brainless sot" is familiar to all. It very often closely resembles that observed in the general paralysis of the insane; which is not remarkable, seeing that the two affections may have in some cases a similar pathology. Now, in alcoholic paraplegia there is every reason to believe that the spinal cord is affected in the same way as these other organs, and the following is the usual condition of the patient:- She lies in bed or on a couch, complaining of severe pains in all the limbs, more especially in the lower ones, which are much wasted, or of a sensation like electric shocks running through them, together with numbness and considerable anæsthesia, and at the same time only slight power of movement, or total inability to stand. With the addition of the akinesia, the symptoms are not unlike those of ataxia, which in its ordinary form appears to be comparatively rare in women. In one case there was hyperæsthesia. In nearly all the cases the liver has been enlarged; there has been sickness, and all the other usual signs of chronic alcoholism. I alluded in $\mathrm{my}$ lecture to the existence of pains in the limbs from which drunkards often suffer before any marked signs of paralysis have shown themselves.

As regards treatment, this is hopeful, and should always be attempted; for I think it must be confessed that it is impossible to tell what kind and amount of change has occurred in the centres to produce paralytic symptoms. If the patient be young and the tissues not much degenerated, I should recommend the ordinary treatment, and especially such medicines as the iodide or bromide of potassium, before commencing galvanism and a tonic course. What, however, I would especially insist upon is the removal of the primary cause of the complaint. This seems a common. sense recommendation; but, I am sorry to say, is one not always enforced. Sometimes the reason is that the doctor fears for bis position as health-proprietor of the family should his hints be offensive, or he has not moral courage to unfold an unpleasant truth. Sometimes, however, he will most conscientiously refrain from recommending a dis. continuance of the alcohol for fear of the results, such as the sudden dissolution of the patient, or an attack of delirium tremens. He need not have the slightest fear on these grounds, for no harm, but only good, will ensue from its withdrawal. I am aware that opinions are at variance in this matter, but nevertheless I enforce my own views strongly, with a large amount of experience to support me. I have never yet seen a person die or suffer from delirium tremens or any other disorder in consequence of the complete withdrawal of alcohol when the system was being poisoned by it. On the other hand, I have seen such remarkable recoveries after its total discontinuance as would certainly surprise those who had never ventured upon the plan. I have seen persons, more especially ladies, lying on their beds surrounded by friends waiting for their last moments, where scarcely a mouthful of food had been taken for months, where the prostration, increased by urgent sickness, was extreme, and where they were constantly plied with brandy to keep them alive a little longer, and yet in such cases, where the diagnosis was clear, from the blood of the patient being overcharged with poisonous elements, and the room stinking with the fetid vapours of the body, I have recommended a withdrawal of every drop of the so-called "stimulus," and with effects more marvellous than anyone who has not adopted the plan can conceive. Unfortunately these cases of alcoholism are so bound up with moral considerations, and in women so often associated with bodily or mental suffering,.that it is most difficult to publish them in all their details. Three cases which I have witnessed during the last year have made a great impression upon me. A lady not far from my residence, the unfortunate subject of alcoholism, and having considerable weakness of the legs, was reduced at length to the utmost stage of prostration by want of food and constant retching. A little brandy was put from time to time between her lips, in order, as was hoped, to eke out her existence a little longer. The end apparently approaching, straw was laid down in front of the house, and her children were sent for in order to take a final farewell, when, after repeated urging on my part, all 
stimulus was suspended. The sickness soon ceased; the blood became gradually depurated; after a few hours a little food was taken; and in a fortnight's time this lady was sitting at the dinner-table with her family. I can say nothing, of course, about the likelihood of relapse, as this opens up another subject. But lately, also, I have been seeing a tradesman and his wife, with Mr. Joyce of Nottinghill, both of whom were addicted to intemperate habits, and both, most remarkably, had almost complete paraplegia. We prevailed on the husband to relinquish his drink, and he began at once to improve; but we had no influence on the female, who was approaching the state of delirium tremens. In another case, that of a medical man, who, after drinking hard, became so ill that he took to his bed, had epileptiform attacks, ate nothing, and was constantly retching, his wife standing over him administering brandy and champagne from time to time to keep him alive a little longer, I succeeded, after several attempts, in inducing his wife and two medical attendants to stop every drop of alcohol. When this was done the patient soon cried out for drink; but, after imploring in vain for some time, he was violently sick, and then sank into a sound sleep. Upon waking he took a little beef-tea, in a few hours ate some solid food, and within a week was back again in his practice.

I do not wish to discuss in this place the merits of alcohol as a remedy, as it is one I constantly use with the utmost advantage; but simply to state my experience that I have never seen the slightest barm accrue from the sudden deprivation of the accustomed stimulus, but, on the other hand, have had the satisfaction of knowing that I have saved fellow-creatures' lives as certainly as if I had plucked them drowning out of the water. I cannot conceive what the objection is to the withdrawal of the alcohol under the circumstances I mention, any more than I can conceive why, when the system is saturated with poison, and the patient dying from the effects of it, such a gross burlesque on the homceopathic doctrine should be practised as to continue administering it.

The purport of this paper is more especially to draw attention to the fact of paralysis, and more particularly spinal paralysis, occurring as a result of alcoholism ; and therefore that when a medical man is called in to see a case of this kind, he should remember intemperance in drinking as a possible cause, just as he would if he found an enlarged liver.

If the affection should turn out to be in any way peculiar in its pathology it will certainly deserve a distinct appellation; but even suould the morbid changes in the cord, together with the resulting symptoms, resemble what is seen in other forms of paralysis, I would still recommend the adoption of such a term as alcoholic paralysis as significant of its cause, for we are warranted in so doing by the use of the expression puerperal, syphilitic, or uræmic epilepsy (eclampsia) in reference to the origin of the fits when arising under special circumstances.

Grosvenor-street, Feb. 1872.

\section{OPHTHALMOSCOPIC DIAGNOSIS OF BRIGHT'S DISEASE.}

BY ASST.- SURG. JOHN LAMBERT, R.N., ROYAL NAVAL HOSPITAL, MALTA.

(Communicated by The Director-Genzral of the Medical Department OF THE NAYY.)

WHILE reading Dr. 'T. Clifford Allbutt's recent work on the Ophthalmoscope in its application to the Diagnosis of the Diseases of the Nervous System and of the Kidneys, it occurred to me that the following case of Bright's disease, diagnosed from the ophthalmoscopic appearances alone, degerved to be recorded as a testimony to the great utility of that instrument in medicine.

I had the advantage of studying ophthalmoscopic medicine and surgery under Drs. Mackenzie, Anderson, Brown, and Rainey, of Glasgow, and as early as 1858 was familiar with the use of the instrument, the examinations being then frequent at the Eye Hospital. From 1860 to $1870 \mathrm{I}$ rarely used it, but when appointed to the Royal Naval Hos- pital at Haslar I again resumed the occasional use of the instrument, stimulated by the example of Staff-Surgeon 3. N. Dick, who, if my memory serves me right, diagnosed case similar to the following one from the examination of the eyes only.

J. H. C- aged forty-five, was brought forward for survey on the 9th of February, 1871, at the Royal Naval Hospital, Malta, for defective vision, supposed to arise frows incipient cataract, the patient also suffering from attacks of dyspepsia and hypochondriasis.

Directed by the Deputy Inspector-General of the hospitall to examine the eyes and to report to him their condition, I applied the catoptric test, but, finding the three images clear and defined, the state of the fundi was next ascertained. In each eye the disc was a little blurred at the edge. the veins unusually large, and the arterial branches small and scattered over the retina. Glistening, irregular, arrowheaded-like and stellar whitish patches were seen in abundance, but particularly crowded round the yellow spot. There were no hæmorrhagic points, and the right eye was more affected than the left. The appearances were so ha. racteristic that retinitis albuminurica was at once diagnosed, and on questioning the patient he informed me that somes years ago he had been invalided from a foreign station for disease of the kidneys, but under treatment at a home hospital he recovered sufficiently to enable him to return duty. Being next desired to micturate, he passed urine freely, of a light-amber colour, which, on being heated of on the addition of nitric acid, deposited albuminous floceule occupying nearly half the fluid, and a microscopic examination of the urine further revealed an advanced stage of Bright's disease, as shown by the presence of fatty granulase casts, and botryoidal clusters of nuclei. The whole examina tion, less the microscopic part, did not occupy over iftees minutes.

On further inquiry it appeared that the patient's gigng had been failing for some time, but not to any noticeable extent. On the 10th of January he observed a dim mistiness before the eyes, which becoming aggravated, he was placed on the sick-list on the 21 st of the same month.

There had been no odema or other symptoms to lead the suspicion of the existence of disease of the kidneze and within a few months of his being invalided he wag said to have had very good sight. The white fatty sclezosis of the retina, however, appeared to be of old standing.

He was invalided and discharged to H.M.S. Hibernes, wait passage to England. I saw him twice afterwards, and examined the ejes once, and found their condition remained the same. On the last cccasion, shortly before he left we: assured me his sight was very much elearer, and he feke confident he would again be fit for duty on board ship. E believe he died shortly after reaching England.

I trust that this communication may be viewed in no other light than as an example of diagnosis of Brighte disease by the aid of the ophthalmoscope. That the diseass was not diagnosed sooner may be excusable on nany grounds, and as regards its earlier determination by ople thalmoscopic examination, an excuse at once presents itsele when Dr. Clifford Allbutt publishes his opinion that "the number of physicians in England who are working with the ophthalmoscope may be counted on the fingers of one hand"; but surely his estimate is too low.

February, 1872.

\section{NOTES ON A CASE OF IDIOPATHIC} TETANUS; RECOVERY.

\section{By JOHN DEARDEN, M.R.C.S.L。}

THe following case of tetanus perhaps may contain sorwe points of interest, from a pathological as well as a thergpeutical point of view; therefore $I$ have thought it might be worthy to be placed before the readers of THE LANCaT.

On the 16th of Norember, 1871, I was called to T. $\mathrm{H}-$ - aged twenty-five, a watchmaker by trade, of sober habits, who had taken a severe cold. When I sare him, at 3 P.M., he was lying on his back; countenance anxious; pulse almost imperceptible, about 100; complainos of excruciating pains across the lumbar and diaphragmatie 